\title{
Small airway dysfunction is associated to excessive bronchoconstriction in asthmatic patients
}

\author{
Veronica Alfieri ${ }^{1}$, Marina Aiello ${ }^{1}$, Roberta Pisi ${ }^{1}$, Panagiota Tzani ${ }^{1}$, Elisa Mariani ${ }^{1}$, Emilio Marangio ${ }^{1}$, Dario Olivieri ${ }^{1}$, \\ Gabriele Nicolini ${ }^{2}$ and Alfredo Chetta ${ }^{{ }^{*}}$
}

\begin{abstract}
Background: We investigated whether a relationship between small airways dysfunction and bronchial hyperresponsiveness (BHR), expressed both in terms of ease of airway narrowing and of excessive bronchoconstriction, could be demonstrated in asthma.

Methods: 63 ( $36 \mathrm{~F}$; mean age $42 \mathrm{yr} \pm 14$ ) stable, mild-to-moderate asthmatic patients ( $F E V_{1} 92 \%$ pred \pm 14 ; FEV $1 / F V C$ $75 \% \pm 8$ ) underwent the methacholine challenge test $(\mathrm{MCT})$. The degree of $\mathrm{BHR}$ was expressed as $\mathrm{PD}_{20}$ (in $\mu \mathrm{g}$ ) and as $\triangle \mathrm{FVC} \%$. Peripheral airway resistance was measured pre- and post-MCT by impulse oscillometry system (IOS) and expressed as R5-R20 (in $\mathrm{KPa} \mathrm{sL}^{-1}$ ).

Results: All patients showed BHR to methacholine $\left(\mathrm{PD}_{20}<1600 \mu \mathrm{g}\right)$ with a $\mathrm{PD}_{20}$ geometric $(95 \% \mathrm{Cl})$ mean value of $181(132-249) \mu \mathrm{g}$ and a $\triangle \mathrm{FVC} \%$ mean value of $13.6 \% \pm 5.1$, ranging 2.5 to $29.5 \%$. 30 out of 63 patients had R5-R20 $>0.03 \mathrm{kPa} \mathrm{sL}^{-1}$ (>upper normal limit) and showed $\Delta \mathrm{FVC} \%$, but not $\mathrm{PD}_{20}$ values significantly different from the 33 patients who had R5-R20 $\leq 0.03 \mathrm{kPa} \mathrm{sL}^{-1}(15.8 \% \pm 4.6$ vs $11.5 \% \pm 4.8, \mathrm{p}<0.01$ and 156(96-254) $\mu \mathrm{g}$ vs 207 (134-322) $\mu \mathrm{g}$, $p=0.382)$. In addition, $\triangle F V C \%$ values were significantly related to the corresponding pre- $(r=0.451, p<0.001)$ and post-MCT ( $r=0.376, p<0.01)$ R5-R20 values.
\end{abstract}

Conclusions: Our results show that in asthmatic patients, small airway dysfunction, as assessed by IOS, is strictly associated to BHR, expressed as excessive bronchoconstriction, but not as ease of airway narrowing.

Keywords: Bronchial hyperresponsiveness, Small airways, Asthma

\section{Introduction}

Asthma is a chronic inflammatory disease affecting the entire tracheo-bronchial tree, from the proximal airways to the peripheral membranous bronchioles, the so-called small airways. The dysfunction of small airways may significantly influence the clinical manifestations and functional aspects of asthma [1]. Small airway obstruction was associated with poor disease control $[2,3]$ and history of asthma exacerbations [3]. Importantly, small airways obstruction seems to significantly contribute to the degree of severity of bronchial hyperresponsiveness (BHR) $[4,5]$, which is a functional hallmark of asthma [6], being a marker of worse disease outcome [7] and a risk factor for asthma development [8]. Notably, low

\footnotetext{
* Correspondence: chetta@unipr.it

${ }^{1}$ Clinical \& Experimental Medicine Department, University of Parma,

Padiglione Rasori, via G. Rasori 10, 43125 Parma, Italy

Full list of author information is available at the end of the article
}

values of the forced expiratory flow between $25 \%$ and $75 \%$ of vital capacity $\left(\mathrm{FEF}_{25-75}\right)$ and of the forced expiratory flow at $50 \%$ of vital capacity $\left(\mathrm{FEF}_{50}\right)$, considering both as measures of small airway patency, were strictly associated to BHR severity in children [4] and in adults [5] with asthma, respectively. In these studies, BHR was assessed as the provocative concentration [4] or dose [5] of methacholine causing a $20 \%$ fall $\left(\mathrm{PC}_{20}\right.$ or $\left.\mathrm{PD}_{20}\right)$ in forced expiratory volume at $1^{\text {st }}$ second $\left(\mathrm{FEV}_{1}\right)$.

It is of note that BHR, expressed as a dose-response curve to methacholine or histamine, may be characterized by two abnormalities consisting in a leftward shift of the dose-response curve (ease of airway narrowing) and in an upward displacement of the maximal response (excessive bronchoconstriction) (Figure 1). The $\mathrm{PD}_{20}$ (or $\mathrm{PC}_{20}$ ), a single point in the dose-response curve, reflects exclusively the ease of airway narrowing. Although both cross-sectional and longitudinal studies have shown 


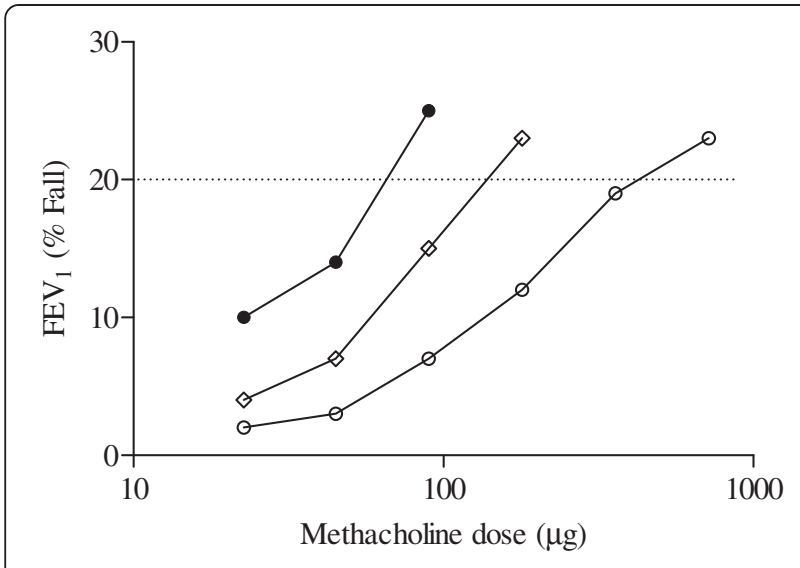

Figure 1 Representative dose-response curves of three asthmatic patients to inhaled methacholine with different slope $(\% / \mu \mathrm{g})$ and $\mathrm{PD}_{20}(\mu \mathrm{g})$ values. Patient A (closed circles) $0.248 \% / \mu \mathrm{g}$ and $72 \mu \mathrm{g}$; patient B (open diamond) $0.112 \% / \mu \mathrm{g}$ and $184 \mu \mathrm{g}$, patient C (open circles) $0.037 \% / \mu \mathrm{g}$ and $625 \mu \mathrm{g}$.

a general relationship between $\mathrm{PD}_{20}$ (or $\mathrm{PC}_{20}$ ) values and severity of asthma, the within subject relationship was weaker [9]. On the other hand, the level of maximal response to the bronchoconstrictor stimuli reflects the propensity for airway closure and is presumably the most important physiopathological abnormality in asthma as long as it may determine fatal risk. Interestingly, excessive bronchoconstriction may be indirectly detected by measuring the fall in lung volume during bronchoprovocation testing.

Studies in humans [10] and in animal models [11,12] have shown that changes in lung volume and in parenchymal elastic load are related to the bronchoconstrictor response to methacholine. Notably, the maximal response of lung resistance to inhaled methacholine increases with decreasing lung volume and elastic recoil pressure [10-12]. Lung volume changes act by altering the forces of interdependence between airways and parenchyma that oppose airway smooth muscle contraction. Based on these findings, Gibbons et al. [13] proposed an indirect method for detection of excessive bronchoconstriction in patients with asthma by measuring the percentage fall in forced vital capacity (FVC) at $\mathrm{PC}_{20}$ $(\triangle \mathrm{FVC} \%)$ during bronchoprovocation testing. This index of airway closure was not related to the $\mathrm{PC}_{20}$ and was as reproducible as $\mathrm{PC}_{20}$ over a long period [13]. Furthermore, $\triangle \mathrm{FVC} \%$ correlated to asthma treatment in adult patients $[13,14]$ and to the presence of symptoms in children with asthma [15].

The functional assessment of small airways is a challenging matter, given that the distal lung is relatively inaccessible for measurements. The ability of spirometry parameters to discriminate small airway obstruction is still debated [16]. On the other hand, the forced oscillation technique has been successfully used as a measure of the airway resistance heterogeneity and gas trapping, giving comparable results to the multiple breath nitrogen washout [17]. Furthermore, the impulse oscillometry system (IOS) has been increasingly used to measure both proximal and peripheral airway resistance in adults $[2,3]$ and children $[18,19]$ with asthma. The main advantage of this simple, noninvasive and sensitive technique [20] is that it does not require forced maneuvers, which may affect bronchial tone.

The aim of the present study was to ascertain whether a relationship between small airways dysfunction and severity of BHR may be demonstrated in patients with mild-to-moderate asthma. Small airway obstruction was assessed by means of IOS and BHR to methacholine was expressed both in terms of $\mathrm{PD}_{20}$, as a measure of ease of airway narrowing, and in terms of $\triangle \mathrm{FVC} \%$, as a measure of excessive bronchoconstriction.

\section{Methods}

\section{Subjects and study design}

Adult patients (16 years of age and older, BMI $\leq 30 \mathrm{~kg} / \mathrm{m}^{2}$ ) with asthma diagnosis according to the international guidelines [21], including current smokers, were eligible to take part in the study and were consecutively recruited from our Asthma Outpatient Clinic.

Between 9 and 12 a.m. on the same day, all patients underwent routine clinical history and physical examination. For each patient, BMI $\left(\mathrm{kg} / \mathrm{m}^{2}\right)$, atopy and asthma therapy were recorded. Asthma control was assessed using the Italian version of the Asthma Control Test [22]. Subsequently as part of their visit, patients underwent IOS before and after methacholine challenge testing (MCT). Patients were advised to omit inhaled bronchodilators $24 \mathrm{~h}$ before IOS and MCT.

The study was performed in accordance with the Good Clinical Practice guidelines recommended by the International Conference on Harmonization of Technical Requirements. The study was approved by the Ethics Committee for the Province of Parma (Italy) and all patients gave their informed consent.

\section{Impulse oscillometry}

Impulse oscillometry was performed using the Jaeger MasterScreen-IOS (Carefusion Technologies, San Diego, CA, USA), following standard recommendations [20]. In short, patients were asked to wear a nose-clip and were seated during tidal breathing with their neck slightly extended and their lips sealed tightly around the mouthpiece, and while firmly supporting their cheeks with their hands. A minimum of three trials, each lasting $30 \mathrm{~s}$, were performed and mean values were taken for each value.

Respiratory resistance at 5 and $20 \mathrm{~Hz}$ ( $\mathrm{R} 5$ and R20, in $\mathrm{kPa} \mathrm{s} \mathrm{^{-1 }}$ ) were used as indices of total and proximal 
airway resistance, respectively and the fall in resistance from 5 to $20 \mathrm{~Hz}$ (R5-R20, in $\mathrm{kPa} \mathrm{s} \mathrm{l}{ }^{-1}$ ) was considered as an index for the resistance of peripheral airways. Moreover, reactance at $5 \mathrm{~Hz}\left(\mathrm{X} 5\right.$, in $\left.\mathrm{kPa} \mathrm{s}^{-1}\right)$ was considered as a representative marker of peripheral airway abnormalities. Data are presented as raw data. An upper limit of normal for R5-R20 was chosen at $0.030 \mathrm{kPa} \mathrm{s} \mathrm{l}^{-1}$, as previously reported [23]. Data obtained in our laboratory in 41 asymptomatic non-smoking subjects $(24 \mathrm{~F}$; age range 24-60 years; BMI range $18.0-29.7 \mathrm{~kg} / \mathrm{m}^{2}$ ) without a history of lung disease and in whom spirometry results were within normal limits fell below these upper limits of normal. Our R5-R20 laboratory data were normally distributed with a mean \pm SD value of $0.021 \pm 0.029 \mathrm{kPa} \mathrm{s} \mathrm{l-1}$ (95\% CI: 0.011-0.030 $\mathrm{kPa} \mathrm{s} \mathrm{l}^{-1}$ ).

Lung function testing and methacholine challenge testing Lung function was measured by a flow-sensing spirometer connected to a computer for data analysis (CPFS/D Spirometer, MedGraphics, St Paul, MN, USA) meeting the American Thoracic Society (ATS) standards. FVC, $\mathrm{FEV}_{1}$ and $\mathrm{FEF}_{25-75}$ were recorded and expressed as percent of predicted value. $\mathrm{FEV}_{1} / \mathrm{FVC}$ was also recorded and expressed as ratio.

Methacholine challenge testing was performed according to a standardized procedure. Each participant inhaled doubling increasing dose of methacholine $(20-2400 \mu \mathrm{g})$, vaporized by a dosimeter with a driving pressure of $180 \mathrm{kPa}$ generating an output of $10 \mu \mathrm{L} /$ puff with particle size within the respirable range $(<5 \mu \mathrm{M})$ (Dosimeter MB3; Mefar, Brescia, Italy). Patients underwent spirometry before and after each inhalation in order to record $\mathrm{FEV}_{1}, \mathrm{FVC}$ and $\mathrm{FEF}_{25-75}$. The test was stopped when either $\mathrm{FEV}_{1}$ fell by $20 \%$ or more from baseline measured after saline inhalation or $2400 \mu \mathrm{g}$ methacholine cumulative dose was reached. $\mathrm{PD}_{20}$ in $\mu \mathrm{g}$ was calculated by linear interpolation of the dose-response curve and the values were log-transformed before analysis. A dose-response slope to methacholine (DRS, $\% / \mu \mathrm{g}$ ) was also calculated by least-squares linear regression analysis. The percentage fall in $\mathrm{FVC}(\triangle \mathrm{FVC} \%)$ at the $\mathrm{PD}_{20}$ relative to the baseline FVC after saline inhalation was also calculated using loglinear interpolation [13].

\section{Statistical analysis}

The distribution of variables was assessed by means of Kolmogorov-Smirnov Goodness-of-Fit test. Variables are expressed as mean \pm SD, unless otherwise specified. Unpaired and paired $t$-test, Mann Whitney test and Pearson $\chi^{2}$ test were used for comparisons, when appropriate. To examine relationships between measures Pearson's correlation coefficient $(r)$ and Spearman rank order correlation coefficient $\left(r_{s}\right)$ were used, when appropriate. The receiver operating characteristic (ROC) curve method
[24] was used to plot the true positive rate (sensitivity) in function of the false positive rate (100-specificity), for different cut-off points of $\triangle \mathrm{FVC} \%$ with respect to R5$\mathrm{R} 20>0.030 \mathrm{kPa} \mathrm{s}^{-1}$, as threshold value. A $p$ value $\leq 0.05$ was considered as significant.

\section{Results}

We consecutively enrolled 71 patients (43 F, age range 16$74 \mathrm{yr}$ ) with asthma severity ranging from mild to severe. Eight patients were excluded due to a $B M I \geq 30 \mathrm{~kg} / \mathrm{m}^{2}$. The 63 included patients showed $\mathrm{FEV}_{1}$ and $\mathrm{FEV}_{1} / \mathrm{FVC}$ values ranging respectively from 65 to $132 \%$ of predicted value and from 58 to $96 \%$. Twenty-one out of 63 asthmatic patients were on ICS (500-1000 mcg/day of beclomethasone dipropionate or equivalent) plus long acting beta2agonists, 9 patients were on ICS alone $(500 \mathrm{mcg} /$ day of beclomethasone dipropionate or equivalent) and the remaining 33 patients controlled their symptoms with inhaled salbutamol prn. Fifty-two patients were atopics (82\%). Forty-nine out of 63 patients (78\%) had well controlled asthma $(\mathrm{ACT}>20)$. In all patients, the ACT median score was 24, ranging from 13 to 25 .

All patients showed BHR to $\mathrm{MCT}\left(\mathrm{PD}_{20}<1600 \mathrm{mcg}\right)$ with a $\mathrm{PD}_{20}$ geometric $(95 \% \mathrm{CI})$ mean value of 181 $(132-249) \mu \mathrm{g}$, a DRS geometric $(95 \% \mathrm{CI})$ mean value of $0.103(0.074-0.143) \% / \mu g$ and with a $\Delta \mathrm{FVC} \%$ mean and median value of $13.5 \% \pm 5$ and $14.0 \%$ respectively, ranging from 2.5 to $29.5 \%$ (Table 1). In all patients, there was no relationship between $\triangle \mathrm{FVC} \%$ and $\mathrm{PD}_{20}(\mathrm{r}=-0.132$; $\mathrm{p}=0.303$ ) (Figure 2). In contrast $\triangle \mathrm{FVC} \%$ and DRS values were weakly but significantly and positively related $(\mathrm{r}=0.260 ; \mathrm{p}=0.039)$ (Figure 3). A significant difference was found in $\triangle \mathrm{FVC}(16.1 \% \pm 5.8$ vs $12.8 \% \pm 4.7 ; \mathrm{p}=0.037)$, but not in $\mathrm{PD}_{20}$ values [143(84-243) $\mu \mathrm{g}$ vs $200(132-286) \mu \mathrm{g}$; $\mathrm{p}=0.431$, when patients were subdivided in poorly controlled $(\mathrm{ACT} \leq 19)$ and in well controlled (ACT > 19) (Figure 4). Pre- and post-MCT R5-R20 values were 0.057 $\mathrm{kPa} \mathrm{s}^{-1} \pm 0.072$ and $0.184 \mathrm{kPa} \mathrm{s}^{-1} \pm 0.148(\mathrm{p}<0.001)$.

When patients were categorized by R5-R20 upper limit of normality [23], 30 out of 63 patients had R5$\mathrm{R} 20>0.030 \mathrm{kPa} \mathrm{s} \mathrm{l}^{-1}$. The two groups of patients significantly differed in $\triangle \mathrm{FVC} \%$ value $(\mathrm{p}<0.01)$, but not in $\mathrm{PD}_{20}$, in DRS and in spirometry values (Table 1 ). In addition, twenty-one out of 30 patients with R5$\mathrm{R} 20>0.030 \mathrm{kPa} \mathrm{s} \mathrm{l}^{-1}$ and 10 out 33 patients with R5$\mathrm{R} 20 \leq 0.030 \mathrm{kPa} \mathrm{s}^{-1}$ had a $\Delta \mathrm{FVC} \%$ value higher than the median value of $\triangle \mathrm{FVC} \%$ of the entire group of patients $\left(X^{2}=7.222, p=0.007\right)$ (Figure 2). As compared to patients with $\leq 0.030 \mathrm{kPa} \mathrm{s} \mathrm{l}{ }^{-1}$, patients with R5$\mathrm{R} 20>0.030 \mathrm{kPa} \mathrm{s} \mathrm{l}^{-1}$ were significantly older and also differed in gender, the vast majority being women. The ratio between the number of atopic and that of non atopic individuals and the ratio between the number of patients with well controlled asthma (ACT >19) and that 
Table 1 Characteristics of patients with asthma

\begin{tabular}{|c|c|c|c|}
\hline & All patients (No. 63) & $\begin{array}{l}\text { Patients with R5-R20 } \\
\leq 0.03 \mathrm{kPa} \mathrm{s}^{-1} \text { (No. } 33 \text { ) }\end{array}$ & $\begin{array}{l}\text { Patients with R5-R20 } \\
>0.03 \mathrm{kPa} \mathrm{s}^{-1} \text { (No. } 30 \text { ) }\end{array}$ \\
\hline Age (years) & $42 \pm 14$ & $38 \pm 12$ & $45 \pm 15^{*}$ \\
\hline $\operatorname{Sex}(F / M)$ & $36 / 27$ & $13 / 20$ & $23 / 7^{* *}$ \\
\hline BMI $\left(\mathrm{kg} / \mathrm{m}^{2}\right)$ & $24 \pm 3$ & $23 \pm 2$ & $25 \pm 3$ \\
\hline Atopy $(\mathrm{Y} / \mathrm{N})$ & $52 / 11$ & $31 / 2$ & $21 / 9^{*}$ \\
\hline Smoking (Y/N) & $12 / 51$ & $9 / 24$ & $4 / 26$ \\
\hline ICS use (Y/N) & $29 / 34$ & $14 / 19$ & $15 / 15$ \\
\hline ICS dose $(\mu \mathrm{g} / \text { day })^{\#}$ & $701 \pm 540$ & $779 \pm 598$ & $628 \pm 490$ \\
\hline$A C T>20 / A C T \leq 19$ & $49 / 14$ & $29 / 4$ & $20 / 10^{*}$ \\
\hline $\mathrm{FEV}_{1}(\%$ of pred) & $92 \pm 14$ & $94 \pm 13$ & $90 \pm 15$ \\
\hline FVC (\% of pred) & $99 \pm 13$ & $102 \pm 12$ & $97 \pm 13$ \\
\hline $\mathrm{FEV}_{1} / \mathrm{SVC}(\%)$ & $75 \pm 8$ & $75 \pm 6$ & $75 \pm 9$ \\
\hline $\mathrm{FEF}_{25-75}$ (\% pred) & $76 \pm 25$ & $77 \pm 21$ & $74 \pm 29$ \\
\hline R5-R20 (kPa s I-1) & $0.057 \pm 0.072$ & $0.011 \pm 0.014$ & $0.108 \pm 0.076^{* *}$ \\
\hline X5 (kPa s l-1) & $-0.134 \pm 0.07$ & $-0.098 \pm 0.02$ & $-0.172 \pm 0.09^{* *}$ \\
\hline $\mathrm{PD}_{20}(\mu \mathrm{g})$ & $181(132-249)$ & $207(134-322)$ & $156(96-254)$ \\
\hline DRS (\%/ug) & $0.103(0.074-0.143)$ & $0.086(0.054-0.135)$ & $0.125(0.076-0.205)$ \\
\hline$\Delta \mathrm{FVC} \%$ & $13.6 \pm 5.1$ & $11.5 \pm 4.8$ & $15.8 \pm 4.6^{* *}$ \\
\hline
\end{tabular}

Values are expressed as mean $\pm \mathrm{SD}$, ratio or geometric mean (Confidence Intervals). \# only in patients using ICS; * $p<0.05$; ${ }^{* *} p<0.01$.

of patients with poorly controlled asthma $(\mathrm{ACT} \leq 19)$ were significantly lower in patients with R5-R20 $>0.030$ $\mathrm{kPa} \mathrm{s}^{-1}$, as compared to the patients with R5-R20 $\leq 0.030$ $\mathrm{kPa} \mathrm{s} \mathrm{l}^{1}$ (2.3 vs $15.5 ; \chi^{2}=6.249, \mathrm{p}=0.012$ and 2.0 vs 7.25 ; $\mathrm{X}^{2}=4.091, \mathrm{p}=0.043$, respectively).

In all patients, $\triangle \mathrm{FVC} \%$ values were significantly related to the corresponding pre- $(\mathrm{r}=0.451, \mathrm{p}<0.001)$ and post-MCT ( $\mathrm{r}=0.376, \mathrm{p}<0.01)$ R5-R20 (Figure 5) and pre- $(\mathrm{r}=-0.502, \mathrm{p}<0.001)$ and post-MCT $(\mathrm{r}=-0.435$,

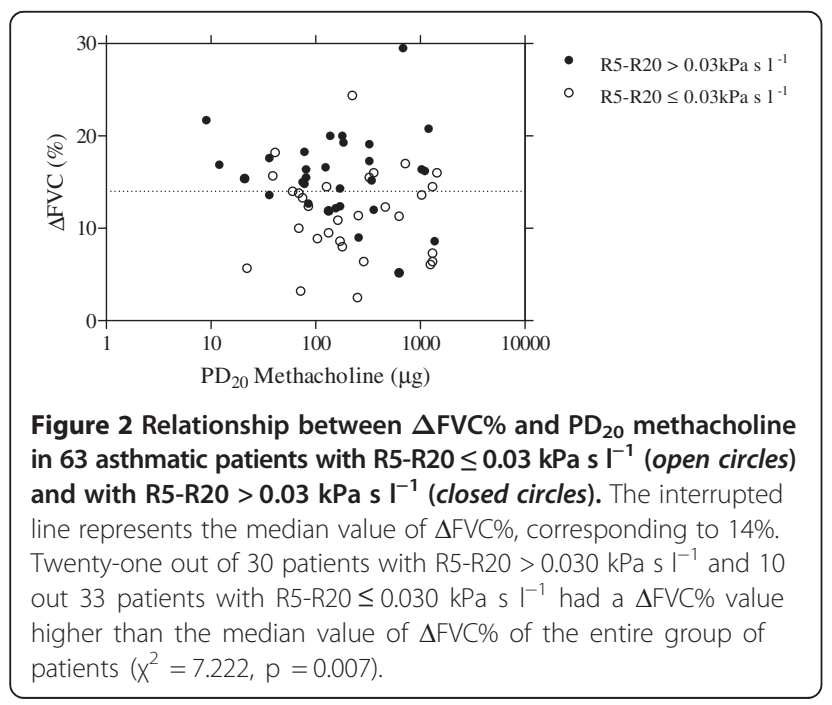

$\mathrm{p}<0.001$ ) X5 (Figure 6) values, but not to the corresponding pre- $(\mathrm{r}=-0.220, \mathrm{p}=0.082)$ and post-MCT $(\mathrm{r}=-0.117$, $\mathrm{p}=0.386) \mathrm{FEF}_{25-75}$ values. In addition, according to the ROC curve method, the plot of the true positive rate in function of the false positive rate for different cut-off points of $\triangle \mathrm{FVC} \%$ with respect to $\mathrm{R} 5-\mathrm{R} 20>0.03 \mathrm{kPa} \mathrm{s} \mathrm{l}-1$, as threshold value, showed a 0.758 ( $\mathrm{p}<0.01$ ) area under curve value. The $\triangle \mathrm{FVC} \%$ cut-off point, which maximized sensitivity and specificity, was $\geq 14.5 \%$ (0.67 sensitivity and 0.76 specificity).

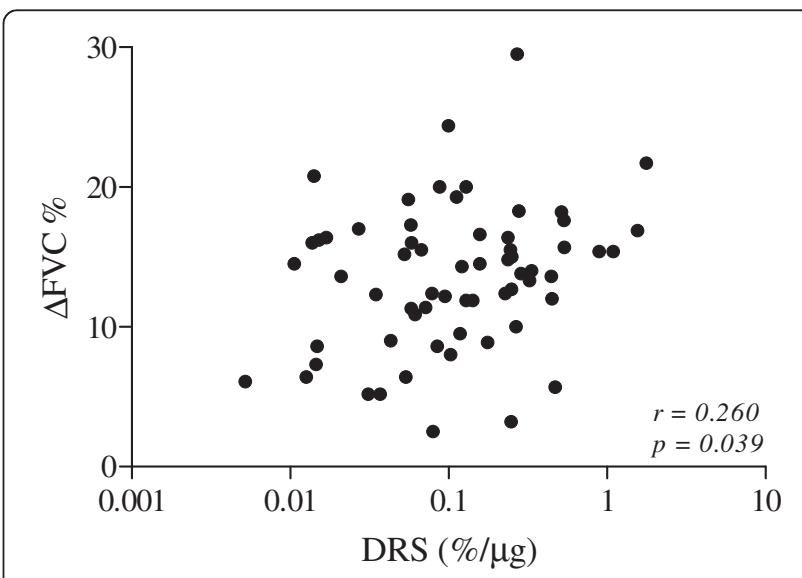

Figure 3 Relationship between $\triangle$ FVC\% and DRS in 63 asthmatic patients. 


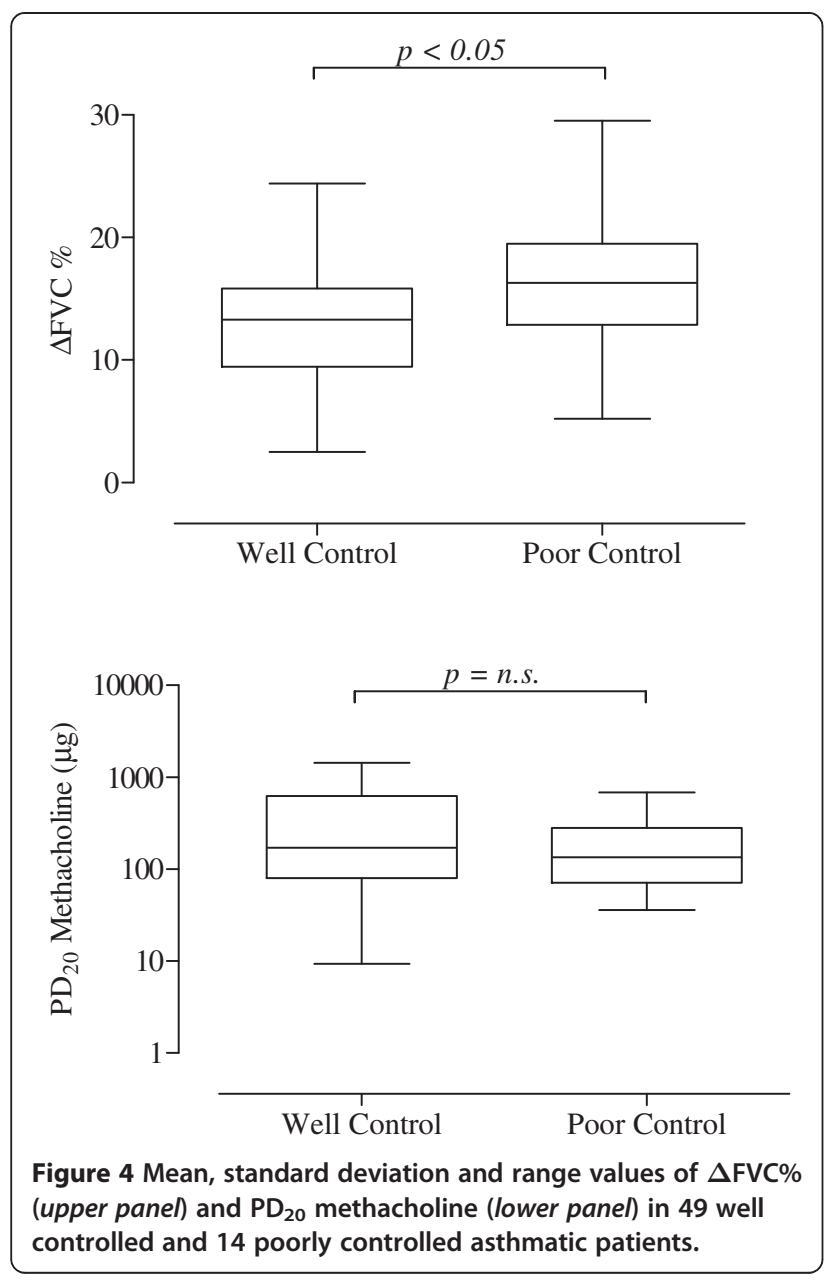

\section{Discussion}

The main finding of this study is that a strict relationship between small airway dysfunction, as assessed by IOS, and bronchial hyperresponsiveness to methacholine is present in patients with mild to moderate asthma. The bronchial hyperresponsiveness can be demonstrated as ease of airway narrowing and as excessive bronchoconstriction expressed as $\mathrm{PD}_{20}$ and $\triangle \mathrm{FVC} \%$, respectively. In the present study, those patients with increased peripheral airway resistance experienced a significantly higher $\triangle \mathrm{FVC} \%$ during the methacholine challenge than patients with normal peripheral airway resistance by showing, on the contrary, similar $\mathrm{PD}_{20}$ values. In addition, patients with small airway dysfunction were older, largely female and with a lower percentage of atopic and well-controlled individuals, as compared to the remaining ones.

Methacholine challenge testing is being used to assess hyperresponsiveness of the entire bronchial tree both in the clinical and research setting. However, whether deposition and effect of inhaled particles of the bronchoconstrictor agent may occur even in the small airways is still open to debate, by relying on different factors, such
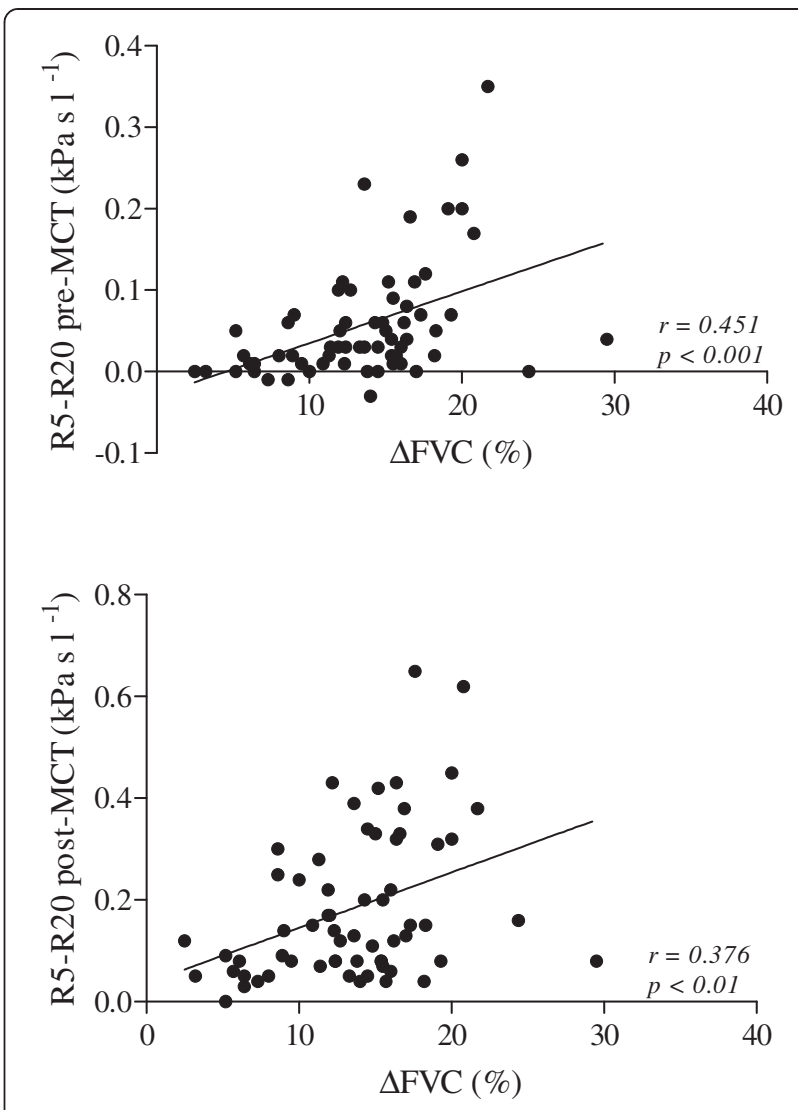

Figure 5 Relationship between $\Delta$ FVC\% and R5-R20 pre-MCT (upper panel) and R5-R20 post-MCT (lower panel) in 63 asthmatic patients.

as inhalation manoeuver and particle size, which is in turn mainly determined by the nebulizer output. In patients with asthma, Cohen et al. [25] investigated whether small and large particle sizes of aerosolized adenosine monophosphate (AMP) lead to similar severity of airway hyperresponsiveness. They found that largeparticle $(9.9 \mu \mathrm{M}) \mathrm{PC}_{20}$ values were smaller than those of standard particles $(3.7 \mu \mathrm{M})$, which in turn were smaller than small-particle $(1.06 \mu \mathrm{M}) \mathrm{PC}_{20}$ values. These findings imply that the airway hyperresponsiveness degree is dependent on the particle size of the inhaled broncoconstrictor agent and, in this case, that small airways also do not show a similar severity of hyperresponsiveness compared to large airways. In our study, we used the MB3 Mefar Dosimeter, a largely used dosimeter, which at the recommended driving pressure of $180 \mathrm{kPa}$ can assure an output with particle size within the respirable range $(<5 \mu \mathrm{M})$ [26]. Accordingly, we may assume that in our asthmatic patients the aerosolized methacholine reached the lower airways by acting in this part of the tracheobronchial tree.

While a $\mathrm{PD}_{20}$ value is measurable in the vast majority of asthma patients during the methacholine challenge, a 


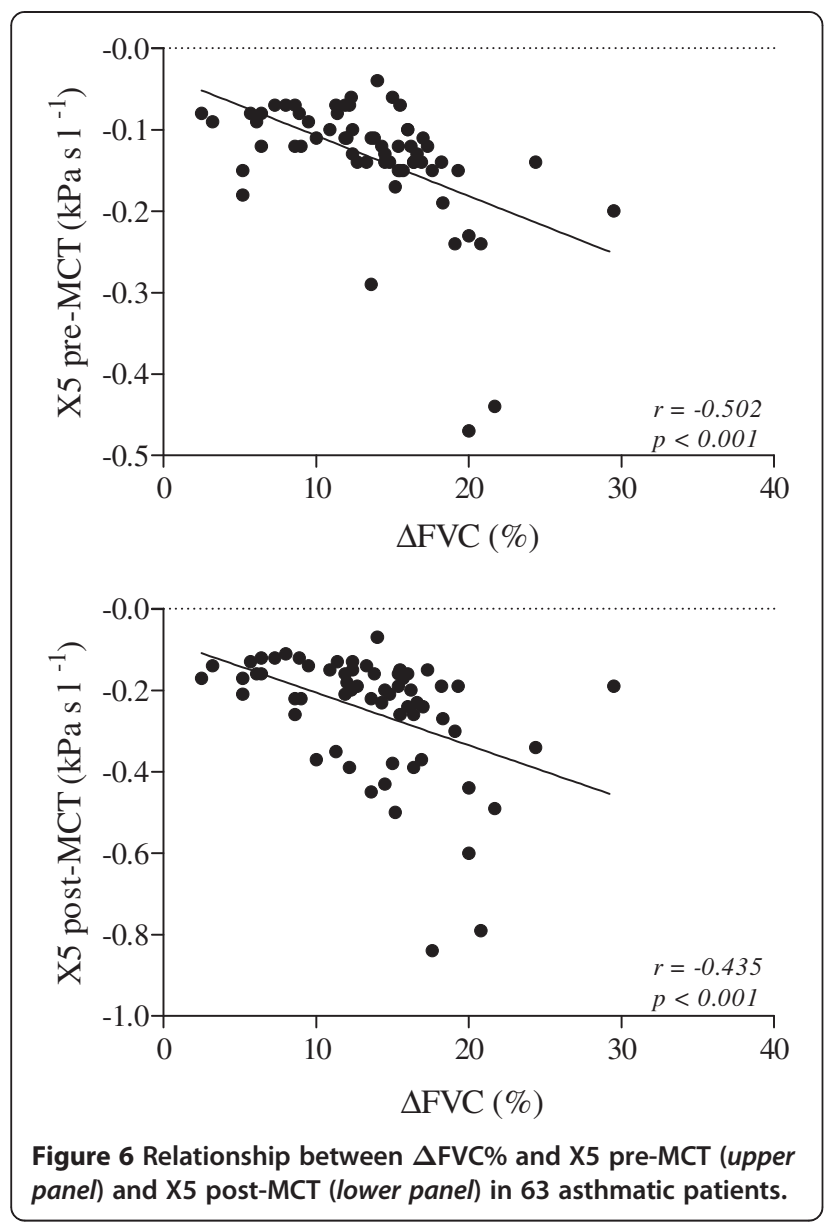

significant $\triangle \mathrm{FVC} \%$ value is not always detectable in asthmatic patients. In the present study, the $\triangle \mathrm{FVC}$ values ranged from 2.5 to $29.5 \%$ with a mean value of $13.6 \% \pm 5.1$ and a normal frequency distribution. Our findings are very similar to those by Gibbons et al. [13] and Abisheganaden et al. [14], who previously reported a mean $\triangle \mathrm{FVC} \%$ of $13.2 \% \pm 5.5$ and $13.8 \% \pm 4.8$, respectively. Moreover, in line with these previous studies $[13,14]$, we also found no relationship between $\triangle F V C \%$ and $\mathrm{PD}_{20}$ values. Patients with the same value of $\mathrm{PD}_{20}$ may show different falls in FVC during methacholine challenge (Figure 2). Taken together, Gibbons et al. [13] Abisheganaden et al. [14] as well as our findings suggest that bronchial hyperresponsiveness in vivo is a composite functional disorder and that the mechanisms underlying excessive bronchoconstriction and ease of airway narrowing during the methacholine challenge are different. In our study, we also found that the $\triangle \mathrm{FVC} \%$ was significantly higher in patients with poorly controlled disease, as compared to well-controlled patients. These results are consistent with the findings of previous studies [13-15] that related $\triangle \mathrm{FVC} \%$ to the severity of asthma and considered it as a useful index in detecting the patients at risk for serious disease.
In the present study, we provide the first evidence that in asthmatic patients excessive bronchoconstriction expressed by $\triangle \mathrm{FVC} \%$ is strictly associated to small airway dysfunction, as assessed by IOS. As compared to patients with R5-R20 $\leq 0.030 \mathrm{kPa} \mathrm{s} \mathrm{l}^{-1}$, patients with R5$\mathrm{R} 20>0.030 \mathrm{kPa} \mathrm{s}^{-1}$ had a high likelihood to be associated to a $\triangle \mathrm{FVC} \%$ greater than $14.5 \%$ during a methacholineinduced bronchoconstriction. Moreover, in all patients we found a significant relationship between the baseline values both of the peripheral airway resistance and reactance, expressed respectively by $\mathrm{R} 5-\mathrm{R} 20$ and $\mathrm{X} 5$, and $\triangle \mathrm{FVC} \%$. Three mechanical factors are called upon to explain the excessive airway narrowing in asthma: an increased contractility of airway smooth muscle induced by humoral mediators or abnormalities in neural control; a lack of a normal inhibiting factor which can prevent further shortening when the smooth muscle begins to shorten, so that the muscle never develops maximum force and degree of shortening; a decrease in elastic load, provided by cartilage and the surrounding parenchyma, so that it is easier to narrow an asthmatic bronchus as compared to a normal bronchus [27]. It is conceivable that the three above mechanisms may be amplified in the peripheral membranous bronchioles, which are without cartilage and, in asthmatic patients, may be the site of intense and extensive processes of inflammation [28-30] and remodeling [31,32]. Thus, inflammatory and structural changes may result in destabilization of these airways, which may become in turn prone to excessive bronchoconstriction. When directly measured in vivo, the small airway reactivity to histamine was significantly enhanced in asthmatic patients relative to normal controls with Isoproterenol being able to completely reverse the increase in peripheral airway resistance in the latter, but not in the former [33].

In line with previous studies, which showed a relationship between small airway dysfunction, as assessed by IOS, and uncontrolled disease, both in adults [2,3] and in children [34,35] with asthma, our group of patients with increased values of peripheral airway resistance had a greater proportion of poorly controlled asthma. Interestingly, these patients did not differ from patients with normal values of peripheral airway resistance in terms of $\mathrm{FEV}_{1}$ and $\mathrm{FEV}_{1} / \mathrm{SVC}$. This is not surprising since patients with severe asthma may show similar airflow obstruction, but significantly increased air trapping, as compared to patients with non severe asthma [36]. Moreover, in our study patients with increased values of peripheral airway resistance were older, largely female and with a lower percentage of atopic individuals, as compared to the patients with normal values of peripheral airway resistance. Whether, age gender or atopy may directly affect the extent of small airway involvement in asthma has up to now not been deeply investigated. In a small group of asthmatic patients, males and females showed different small airways impairment 
[37]. Interestingly, males exhibited small airway involvement by attenuated small airway patency and females by small airway inflammation [37]. Air trapping, older age, female gender and less atopy were also significantly associated to the severe asthma phenotype [38].

\section{Conclusion}

The present study shows that mild-to-moderate asthmatic patients with small airway dysfunction, as assessed by IOS, have excessive bronchoconstriction during the methacholine challenge, which is an important index of disease severity. Though association does not imply causality, the results of our study suggest a significant contribution of small airways in the pathophysiology of bronchial hyperresponsiveness. This fact may have implications for the treatment of asthmatic patients by increasing in importance the small-particle aerosols.

\section{Abbreviations \\ BHR: Bronchial hyperresponsiveness; DRS: Dose-response curve slope; $\mathrm{FEV}_{1}$ : Forced expiratory volume at 1st second; FVC: Forced vital capacity; $\Delta$ FVC\%: Percentage fall in FVC at $\mathrm{PD}_{20}$; IOS: Impulse oscillometry system; MCT: Methacholine challenge test; $\mathrm{PD}_{20}$ : Dose of methacholine causing a 20\% fall in FEV ; R5-R20: Fall in resistance from 5 to $20 \mathrm{~Hz}$.}

\section{Competing interests}

The authors declare that they have no competing interests.

\section{Authors' contributions}

VA served as the primary author. She developed the study protocol, participated in the patients recruitment and statistical analysis and drafted the manuscript and she is the guarantor of the entire manuscript. MA, RP, PT and EM participated in the design of the study and helped to patients recruitment. EM, DO and GN participated in the coordination of the study and helped to draft the manuscript. AC developed the study protocol, interpreted study data, contributed to and reviewed drafts of the manuscript. All authors read and approved the final manuscript.

\section{Acknowledgements}

The authors gratefully acknowledge the patients who volunteered for this study and Ms. Maria Pia Salati, Lung Function Unit of the University Hospital of Parma, for performing pulmonary function testing. No extramural funding was used to support the study.

\section{Author details}

'Clinical \& Experimental Medicine Department, University of Parma, Padiglione Rasori, via G. Rasori 10, 43125 Parma, Italy. ${ }^{2}$ Corporate Clinical Development, Chiesi Farmaceutici S.p.A, Parma, Italy.

Received: 1 April 2014 Accepted: 20 July 2014

Published: 27 August 2014

\section{References}

1. van den Berge M, ten Hacken NH, Cohen J, Douma WR, Postma DS: Small airway disease in asthma and COPD: clinical implications. Chest 2011, 139:412-423.

2. Takeda T, Oga T, Niimi A, Matsumoto H, Ito I, Yamaguchi M, Matsuoka H, Jinnai M, Otsuka K, Oguma T, Nakaji H, Chin K, Mishima M: Relationship between small airway function and health status, dyspnea and disease control in asthma. Respiration 2010, 80:120-126.

3. Pisi R, Tzani P, Aiello M, Martinelli E, Marangio E, Nicolini G, Olivieri D, Chetta A: Small airway dysfunction by impulse oscillometry in asthmatic patients with normal forced expiratory volume in the 1st second values. Allergy Asthma Proc 2013, 34:e14-e20.

4. Simon MR, Chinchilli VM, Phillips BR, Sorkness CA, Lemanske RF Jr, Szefler SJ, Taussig L, Bacharier LB, Morgan W, Childhood Asthma Research and
Education Network of the National Heart, Lung, and Blood Institute: Forced expiratory flow between $25 \%$ and $75 \%$ of vital capacity and FEV1/forced vital capacity ratio in relation to clinical and physiological parameters in asthmatic children with normal FEV1 values. J Allergy Clin Immunol 2010, 126:527-534.

5. Telenga ED, van den Berge $M$, Ten Hacken NH, Riemersma RA, van der Molen T, Postma DS: Small airways in asthma: their independent contribution to the severity of hyperresponsiveness. Eur Respir J 2013, 41:752-754.

6. Cockcroft DW, Davis BE: Mechanisms of airway hyperresponsiveness. J Allergy Clin Immunol 2006, 118:551-559.

7. Jansen DF, Schouten JP, Vonk JM, Rijcken B, Timens W, Kraan J, Weiss ST, Postma DS: Smoking and airway hyperresponsiveness especially in the presence of blood eosinophilia increase the risk to develop respiratory symptoms: a 25-year follow-up study in the general adult population. Am J Respir Crit Care Med 1999, 160:259-264.

8. Peat JK, Woolcock AJ, Cullen K: Rate of decline of lung function in subjects with asthma. Eur J Respir Dis 1987, 70:171-179.

9. Josephs LK, Gregg I, Holgate ST: Does non-specific bronchial responsiveness indicate the severity of asthma? Eur J Respir Dis 1990, 3:220-227.

10. Ding DJ, Martin JG, Macklem PT: Effects of lung volume on maximal methacholine-induced bronchoconstriction in normal humans. J Appl Physiol 1987, 62:1324-1330.

11. Sly PD, Brown KA, Bates JH, Macklem PT, Milic-Emili J, Martin JG: Effect of lung volume on interrupter resistance in cats challenged with methacholine. J Appl Physiol 1988, 64:360-366.

12. Robatto FM, Simard S, Orana H, Macklem PT, Ludwig MS: Effect of lung volume on plateau response of airways and tissue to methacholine in dogs. J Appl Physiol 1992, 73:1908-1913.

13. Gibbons WJ, Sharma A, Lougheed D, Macklem PT: Detection of excessive bronchoconstriction in asthma. Am J Respir Crit Care Med 1996, 153:582-589.

14. Abisheganaden J, Chan C-C, Chee CBE, Wang Y-T: Methacholine-induced fall in forced vital capacity as a marker of asthma severity. Respir Med 1999, 93:277-282.

15. Yoo Y, Choung JT, Yu J, Kim do K, Choi SH, Koh YY: Comparison of percentage fall in FVC at the provocative concentration of methacholine causing a $20 \%$ fall in FEV1 between patients with asymptomatic bronchial hyperresponsiveness and mild asthma. Chest 2007, 132:106-111.

16. Burgel P-R: The role of small airways in obstructive airway diseases. Eur Respir Rev 2011, 20:23-33.

17. King GG, Downie SR, Verbanck S, Thorpe CW, Berend N, Salome CM, Thompson B: Effects of methacholine on small airway function measured by forced oscillation technique and multiple breath nitrogen washout in normal subjects. Respir Physiol Neurobiol 2005, 148:165-177.

18. Song TW, Kim KW, Kim ES, Park JW, Sohn MH, Kim KE: Utility of impulse oscillometry in young children with asthma. Pediatr Allergy Immunol 2008, 19:763-768

19. Komarow HD, Skinner J, Young M, Gaskins D, Nelson C, Gergen PJ, Metcalfe DD: A study of the use of impulse oscillometry in the evaluation of children with asthma: analysis of lung parameters, order effect, and utility compared with spirometry. Pediatr Pulmonol 2012, 47:18-26.

20. Oostveen E, MacLeod D, Lorino H, Farré R, Hantos Z, Desager K, Marchal F, ERS Task Force on Respiratory Impedance Measurements: The forced oscillation technique in clinical practice: methodology, recommendations and future developments. Eur Respir J 2003, 22:1026-1041

21. Bateman ED1, Hurd SS, Barnes PJ, Bousquet J, Drazen JM, FitzGerald M, Gibson P, Ohta K, O'Byrne P, Pedersen SE, Pizzichini E, Sullivan SD, Wenzel SE, Zar HJ: Global strategy for asthma management and prevention: GINA executive summary. Eur Respir J 2008, 31:143-178.

22. Nathan RA, Sorkness CA, Kosinski M, Schatz M, Li JT, Marcus P, Murray JJ, Pendergraft TB: Development of the asthma control test: a survey for assessing asthma control. J Allergy Clin Immunol 2004, 113:59-65.

23. Williamson PA, Clearie K, Menzies D, Vaidyanathan S, Lipworth BJ: Assessment of small-airways disease using alveolar nitric oxide and impulse oscillometry in asthma and COPD. Lung 2011, 189:121-129.

24. Zweig MH, Campell G: Receiver-operating characteristic (ROC) plots: a fundamental evaluation tool in clinical medicine. Clin Chem 1993, 39:561-577. 
25. Cohen J, Postma DS, Douma WR, Vonk JM, De Boer AH, ten Hacken NHT: Particle size matters: diagnostic and treatment of small airways involvement in asthma. Eur Respir J 2011, 37:532-540.

26. Ward RJ, Liakakos P, Leonard RF, Reid DW, Johns DP, Walters EH: A critical evaluation of the Mefar ${ }^{\mathrm{TM}}$ dosimeter. Eur Respir J 1999, 14:430-434.

27. Macklem PT: Mechanical factors determing maximum bronchoconstriction. Eur Respir J 1989, 2(Suppl 6):516s-519s.

28. Hamid Q, Song Y, Kotsimbos TC, Minshall E, Bai TR, Hegele RG, Hogg JC: Inflammation of small airways in asthma. J Allergy Clin Immunol 1997, 100:44-51.

29. Tulic MK, Christodoulopoulos P, Hamid Q: Small airway inflammation in asthma. Respir Res 2001, 2:333-339.

30. Balzar S, Wenzel SE, Chu HW: Transbronchial biopsy as a tool to evaluate small airways in asthma. Eur Respir J 2002, 20:254-259.

31. Kuwano K, Bosken CH, Paré PD, Bai TR, Wiggs BR, Hogg JC: Small airways dimensions in asthma and in chronic obstructive pulmonary disease. Am Rev Respir Dis 1993, 148:1220-1225.

32. Dolhnikoff M, da Silva LF, de Araujo BB, Gomes HA, Fernezlian S, Mulder A, Lindeman JH, Mauad T: The outer wall of small airways is a major site of remodeling in fatal asthma. J Allergy Clin Immunol 2009, 123:1090-1097.

33. Wagner EM, Bleecker ER, Permutt S, Liu MC: Direct assessment of small airways reactivity in human subjects. Am J Respir Crit Care Med 1998, 157:447-452.

34. Shi Y, Aledia AS, Tatavoosian AV, Vijayalakshmi S, Galant SP, George SC Relating small airways to asthma control by using impulse oscillometry in children. J Allergy Clin Immunol 2012, 129:671-678.

35. Shi Y, Aledia AS, Galant SP, George SC: Peripheral airway impairment measured by oscillometry predicts loss of asthma control in children. J Allergy Clin Immunol 2013, 131:718-723.

36. Sorkness RL, Bleecker ER, Busse WW, Calhoun WJ, Castro M, Chung KF, Curran-Everett D, Erzurum SC, Gaston BM, Israel E, Jarjour NN, Moore WC Peters SP, Teague WG, Wenzel SE, National Heart, Lung, and Blood Institute Severe Asthma Research Program: Lung function in adults with stable but severe asthma: air trapping and incomplete reversal of obstruction with bronchodilation. J Appl Physiol 2008, 104:394-403.

37. Cohen J, Douma WR, ten Hacken NHT, Oudkerk M, Postma DS: Physiology of the small airways: A gender difference? Respir Med 2008, 102:1264-1271.

38. Moore WC, Meyers DA, Wenzel SE, Teague WG, Li H, Li X, D'Agostino R Jr, Castro M, Curran-Everett D, Fitzpatrick AM, Gaston B, Jarjour NN, Sorkness R, Calhoun WJ, Chung KF, Comhair SA, Dweik RA, Israel E, Peters SP, Busse WW, Erzurum SC, Bleecker ER, National Heart, Lung, and Blood Institute's Severe Asthma Research Program: Identification of asthma phenotypes using cluster analysis in the Severe Asthma Research Program. Am J Respir Crit Care Med 2010, 181:315-323.

doi:10.1186/s12931-014-0086-1

Cite this article as: Alfieri et al: Small airway dysfunction is associated to excessive bronchoconstriction in asthmatic patients. Respiratory Research 2014 15:86.

\section{Submit your next manuscript to BioMed Central and take full advantage of:}

- Convenient online submission

- Thorough peer review

- No space constraints or color figure charges

- Immediate publication on acceptance

- Inclusion in PubMed, CAS, Scopus and Google Scholar

- Research which is freely available for redistribution 